\title{
Evaluasi Website Rakuten Indonesia dengan Eyetracking Usability Testing
}

\author{
Yani Herawati ${ }^{1 *}$, Sandy Halim ${ }^{2}$, Ceicalia Tesavrita ${ }^{3}$ \\ $1 *, 2,3)$ Fakultas Teknologi Industri, Jurusan Teknik Industri, Universitas Katolik Parahyangan, \\ Jl. Ciumbuleuit 94, Bandung 40141, \\ email : yani.herawati@unpar.ac.id, 1 , sandyhalim_93@live.com ${ }^{2}$, ceicalia@unpar.ac.id ${ }^{3}$
}

\begin{abstract}
Abstrak
The increasing internet users in Indonesia has encourage companies to take advantage of internet technology in its business (e-commerce). Amid the growth of e-commerce, Rakuten Indonesia (RI) as one of the e-commerce company, have to compete in order to retain its existence. For e-commerce companies, websites usability has an important role in attracting consumers to conduct transactions. RI websites usability will be evaluated using Eyetracking usability testing. Eyetracking usability testing use the results of the gaze replay, gaze plots, heat maps, and the area of interest (AOI). The evaluation was done for the website features (product categorization, filtering products, sorting products, product description, saving products, as well as ordering the product), and the placement of the advertisement on the homepage RI website. From the evaluation, it was found 10 problems related RI websites feature and the improvements was made. From the results of the evaluation of advertisements placements based AOI, can be determined the cost of advertising and the content of the advertisement on a specific area on the website's homepage.
\end{abstract}

Keywords: usability, e-commerce, website, eyetracking usability testing.

\begin{abstract}
Abstrak
Peningkatan pengguna internet di Indonesia mendorong banyak perusahaan untuk memanfaatkan teknologi internet dalam usahanya (e-commerce). Ditengah pertumbuhan e-commerce, Rakuten Indonesia (RI) sebagai salah satu perusahaan e-commerce, harus mampu bersaing agar tetap mempertahankan eksistensinya. Bagi perusahaan e-commerce, kemampupakaian website memiliki peranan yang penting dalam menarik minat konsumen untuk melakukan transaksi. Kemampupakaian website RI akan dievaluasi menggunakan eyetracking usability testing dengan melihat hasil dari gaze replay, gaze plot, heat map, dan area of interest (AOI). Evaluasi dilakukan untuk fitur website (pengkategorian produk, filter produk, pengurutan produk, deskripsi produk, penyimpanan barang yang diminati, serta pemesanan produk), dan penempatan posisi iklan pada homepage website RI. Dari hasil evaluasi, ditemukan 10 permasalahan terkait fitur website RI yang kemudian dilakukan perbaikan. Dari hasil evaluasi penempatan iklan berdasarkan AOI dapat ditentukan biaya iklan dan isi dari iklan pada area tertentu di homepage website RI.
\end{abstract}

Kata Kunci: kemampupakaian e-commerce, website, eyetracking usability testing.

\section{Pendahuluan}

Seiring dengan pertumbuhan teknologi serta kemudahaan mendapatkan akses internet, membuat pengguna internet di Indonesia semakin

* Korespondensi Penulis bertambah. Berdasarkan data yang diperoleh dari Statista (2015), pada tahun 2014 jumlah pengguna internet sebanyak 83.7 juta, dengan peningakatan sebesar 10.9 juta pengguna dibandingkan tahun 2013. Diprediksikan pada tahun 2019 akan ada sebanyak 123 juta pengguna internet. Melihat pertumbuhan peng- 
guna internet semakin meningkat, membuat perusahaan mulai memanfaatkan teknologi internet. Perusahaan yang memanfaatkan teknologi internet untuk menjual/ mempromosikan produk/ jasanya disebut dengan istilah e-commerce. E-commerce memiliki beberapa keuntungan diantaranya jangkauan konsumen yang luas, kemudahan komunikasi, interaktif, dan fleksibel. Pada perusahaan e-commerce, website merupakan salah satu bagian yang penting karena berperan sebagai mediator perusahaan dengan konsumen. Selain website dapat berfungsi dengan baik, kemampupakaian dari sebuah website perlu diperhatikan agar konsumen merasa nyaman ketika menggunakan website tersebut. Penelitian ini menggunakan obyek: Website Rakuten Indonesia (RI) yang merupakan website jual beli yang menawarkan berbagai produk dari beberapa toko. Produk yang ditawarkan di website RI bervariasi, seperti produk makanan, pakaian, barang elektronik, otomotif, dan sebagainya. Fungsi utama website RI sebagai media jual-beli produk sehingga konsumen dapat menggunakan website RI sebagai tempat berbelanja. Untuk mengidentifikasi permasalahan terkait website RI, dilakukan penelitian pendahuluan dengan cara mewawancarai 9 responden. Responden yang dipilih adalah responden yang sudah terbiasa menggunakan internet dan pernah melakukan transaksi pembelanjaan secara online. Teknik sampling yang digunakan adalah convenience sampling. Dari penelitian pendahuluan yang dilakukan, fungsi utama website RI sudah terpenuhi, tetapi masih terdapat beberapa kendala dalam penggunaan website RI. Beberapa kendala yang dialami pengguna website RI diantarnya: penulisan subkategori tidak teratur sehingga menyulitkan pengguna pada saat mencari kategori produk tertentu, informasi produk kurang lengkap dan tidak terstruktur sehingga pengguna kesulitan dalam mencari informasi produk, serta gambar produk tidak ditampilkan dalam detail produk. Dari permasalahan yang diidentifikasi, maka diperlukan evaluasi website RI. Evaluasi website RI dilakukan dengan menggunakan metode eyetracking. Eyetracking usability testing memiliki kelebihan dapat melihat pergerakan mata pengguna saat melihat suatu tampilan. Dengan mengamati pergerakan mata, dapat diketahui ketika pengguna mengalami kesulitan dan dapat diketahui apakah elemen suatu tampilan mengalihkan perhatian pengguna (Ross, 2009). Dengan demikian perumusan masalah dalam penelitian ini adalah sebagai berikut: bagaimana evaluasi website RI dan bagaimana rancangan usulan untuk website RI.

\section{Tinjauan Pustaka}

E-commerce merupakan semua pertukaran informasi dengan media elektronik antara sebuah organisasi dengan pihak ketiga yang berhubungan. E-commerce tidak hanya sebatas pembelian/ penjualan produk, tetapi juga aktivitas sebelum dan sesuai penjualan dalam rantai pasok (Chaffey, 2009). Berdasarkan Mc. Grath (2013), faktor yang membuat website e-commerce menjadi lebih mudah digunakan diantaranya: navigasi yang rapi membuat pengguna nyaman saat menjelajahi website, menemukan informasi, membandingkan produk, dan melakukan pembayaran dengan singkat, halaman muka website dan tulisan yang mudah dibaca, desain fitur menambahkan ke keranjang belanja (add to cart button), sistem keamanan website, penawaran khusus, serta navigasi dalam bentuk tulisan yang menujukkan laman yang dibuka dalam hirarki sebuah website (breadcrumb). Menurut Jordan (2000), hirarki kebutuhan manusia terdiri dari 3 tingkatan, yaitu: functionality, usability (kemampupakaian), dan pleasure. Kemampupakaian merupakan atribut kualitas yang menilai kemudahan user interface yang digunakan (Nielson, 2012). Kemampupakaian suatu produk tercapai ketika produk/ layanan dapat digunakan untuk mencapai apa yang pengguna harapkan tanpa adanya halangan, keraguan, atau pertanyaan (Rubin dan Chisnell, 2008). Menurut Rubin dan Chisnell (2008), suatu produk dapat dikatakan mampu pakai jika memenuhi 6 kriteria kemampupakaian minimal 70\%. Keenam kriteria kemampupakaian tersebut adalah: usefulness, efficiency, effectiveness, learnability, satisfaction, dan accessibility. Pengujian kemampupakaian merupakan proses pengujian dan evaluasi kriteria kemampupakaian pada suatu produk dengan menggunakan responden yang sesuai target pasar untuk produk tersebut. Eye tracking adalah proses menunjukkan kemana orang melihat, mengikuti, dan merekam pergerakan titik yang dilihat (Rouse, 2013). Eye tracking memiliki keuntungan meningkatkan tampilan halaman dan untuk mengetahui kebiasaan manusia. Dalam meningkatkan tampilan muka, eye gaze menyediakan metode yang sangat efisien dalam menunjukkan sesuatu sehingga dapat diketahui kemana fokus mata dan pergerakan mata. Mata akan menuju tempat yang memilliki informasi yang sedang dicari, sehingga dengan mengamati apa yang dilihat oleh pengguna, dapat dikethui informasi apa yang sedang diproses (http://www.tobii.com/en/abouttobii/what-is-eye-tracking/). Menurut Ross (2009), teknologi eye tracking dapat memberikan infor- 
masi tambahan dalam mengidentifikasi masalah kemampupakaian dan menginterpretasikan desain. Visualisasi dapat dilakukan melalui gaze replay, gaze plots, heat maps, dan area of interest (AOI). Menurut Pernice dan Nielsen (2009), Gaze replay memungkinkan untuk mengulang kembali pergerakan mata pada saat pengujian dilakukan sehingga dapat melihat apa yang diamati oleh pengguna. Gaze plots menampilkan urutan pergerakan dan posisi fiksasi, serta pergerakan mata yang terjadi antar fiksasi pada gambar yang diamati. Heat maps memberikan highlight pada area gambar yang terjadi fiksasi penglihatan pengguna. Menurut Holmqvist (2014), Area of interest menujukkan area dengan tingkat konsentrasi penglihatan paling tinggi dan dapat menganalisis tampilan tanpa ada faktor subyektif. Berdasarkan Tobii Technology (2012), Software Tobii Studio dapat memberikan analisis metrik berdasarkan data yang diperoleh dari pengujian eye tracking dengan membuat AOI pada media yang tersedia. Matriks yang digunakan adalah time to first fixation dan fixation duration. Time to first fixation mengukur lama waktu yang dibutuhkan oleh responden untuk melakukan fiksasi pada suatu AOI untuk pertama kali. Fixation duration mengukur durasi untuk setiap fiksasi yang terjadi pada suatu AOI.

\section{Hasil dan Pembahasan}

\subsection{Evaluasi Website Awal}

Evaluasi website RI diawali dengan mengidentifikasi kebutuhan. Proses identifikasi dilakukan dengan metode wawancara terhadap 25 pengguna website e-commerce sejenis Rakuten Indonesia (RI), seperti Lazada, Zalora, dan lainlain. Teknik sampling yang digunakan adalah convenience sampling. Dari proses ini diidentifikasi 39 kebutuhan, yang kemudian dikelompokan kedalam bentuk hirarki. Hirarki kebutuhan yang dihasilkan adalah: website memiliki tampilan menarik, website memiliki tampilan yang mudah dipahami, website memiliki fitur yang mendukung kemudahan dalam pencarian produk, website memberikan informasi yang jelas, serta website mendukung kemudahan proses pemesanan. Hirarki kebutuhan tersebut digunakan sebagai dasar perancangan dalam pengujian kemampupakaian website RI. Setelah diidentifikasi kebutuhan, dilakukan pengujian kemampupakaian website RI dengan menggunakan alat bantu eyetracker. Jumlah responden yang digunakan dalam dalam penelitian ini se- banyak 39 orang agar dapat dilakukan analisis terhadap heat map pergerakan mata. Kriteria responden yang dilibatkan dalam penelitian yaitu terbiasa menggunakan komputer dan internet, serta melakukan transaksi di website e-commerce minimal 1 kali dalam 3 bulan terakhir. Teknik sampling yang digunakan adalah convenience sampling. Pengujian kemampupakaian dilakukan di sebuah lingkungan terkontrol. Hanya terdapat satu orang responden dan satu orang pengamat dalam satu ruangan agar responden dapat berkonsentrasi dalam menyelesaikan tugas. Pengujian kemampupakaian website RI diawali dengan pemberian penjelasan mengenai eyetracking. Setelah penjelasan, responden diberikan task scenario untuk menguji kemampupakian website, selain itu diberikan juga kuesioner untuk penilaian website RI. Setelah pengujian dilakukan, responden akan diwawancarai mengenai pengalaman selama menggunakan website RI dengan diputar video gaze replay. Dalam penelitian ini digunakan 4 (empat) task scenario yang akan dilakukan secara terpisah. Task I: responden diminta untuk menjelajahi website selama 20 detik. Task ini yang bertujuan agar responden dapat menilai tampilan website RI dan untuk mengetahui elemen-elemen pada website RI yang menarik perhatian responden. Task II: membuka daftar smartphone merk Samsung dan LG dengan harga Rp 1.000.000 Rp 3.000.000. Task III: membaca deskripsi produk yang memiliki harga termurah dari hasil pencarian sebelumnya lalu didaftarkan ke wishlist. Task IV: melakukan pembelian pada barang yang telah didaftarkan pada wishlist sejumlah 2 unit. Kriteria kemampupakaian yang digunakan dalam penelitian ini adalah effectiveness dan efficiency. Effectiveness terkait dengan kesuksesan dalam memenuhi kebutuhan pengguna dan kemudahan pengunaan. Hasil penilaian effectiveness website RI melalui task II-IV dapat dilihat pada Tabel 1. Effectiveness dihitung dengan melihat presentase kesuksesan responden pada saat melaksanakan tasks yang dilakukan.

Tabel 1: Persentase Kesuksesan

\begin{tabular}{|l|c|c|c|}
\hline & Task II & TaskIII & TaskIV \\
\hline $\begin{array}{l}\text { Persentase } \\
\text { Kesuksesan }\end{array}$ & 100 & 100 & 41.03 \\
\hline
\end{tabular}

Pada pengerjaan task IV, banyak responden yang tidak dapat menyelesaikannya karena responden tidak memilih button perbarui, sehingga jumlah barang yang dibeli tidak diperbarui sejumlah 2 unit. Efficiency terkait den- 
gan waktu yang diperlukan dalam pemenuhan kebutuhan pengguna. Hasil penilaian efficiency website RI melalui task II-IV dpat dilihat pada Tabel 2. Efficiency dihitung dengan membandingkan jumlah responden yang sukses menyelesaikan task dibawah waktu standar dengan jumlah respon yang sukses menyelesaikan task tersebut.

Tabel 2: Persentase Efficiency

\begin{tabular}{|l|c|c|c|}
\hline & Task II & Task III & Task IV \\
\hline $\begin{array}{l}\text { Jumlah respon- } \\
\text { den yang sukses }\end{array}$ & 39 & 39 & 16 \\
\hline $\begin{array}{l}\text { Jumlah respon- } \\
\text { den di bawah } \\
\text { waktu standar }\end{array}$ & 18 & 8 & 4 \\
\hline Efisiensi & 46.15 & 20.51 & 25 \\
\hline
\end{tabular}

Dalam pengerjaan tasks, ketika dibandingkan dengan langkah standar atau waktu standar pengerjaan task, terdapat beberapa permasalahan yang diantaranya: kesalahan dalam memilih menu dan rentang harga, beberapa responden tidak memanfaatkan fitur sortir produk, tidak menggunakan button perbarui untuk memperbarui jumlah unit yang dibeli, dan kesulitan dalam mencari button wishlist. Selain menjalankan tasks, responden diminta untuk memberikan penilaiannya terhadap website RI, diantaranya:

1. Website RI memiliki tampilan yang menarik.

2. Website RI memiliki tampilan yang mudah dipahami.

3. Sistem pemesanan pada website RI mudah digunakan.

4. Website RI memiliki informasi (deskripsi produk, pemesanan, pembayaran, dan sebagainya) yang jelas.

Hasil penilaian dapat dilihat pada Gambar 1 sampai dengan Gambar 4.

Analisa hasil eyetracking dilakukan dengan melihat gaze replays. Gaze plot digunakan untuk menggambarkan pola penglihatan responden. Dari analisa hasil eyetracking untuk task II, ditemukan adanya kesulitan pada saat menggunakan website RI, yaitu penyusunan pilihan dalam subkategori yang tidak teratur sehingga responden menghabiskan waktu lebih lama pada saat melihat bagian subkategori dan kesulitan melihat angka pada saat menentukan rentang harga. Hal ini dapat dilihat pada gaze plot salah satu responden (Gambar 5 dan Gambar 6).

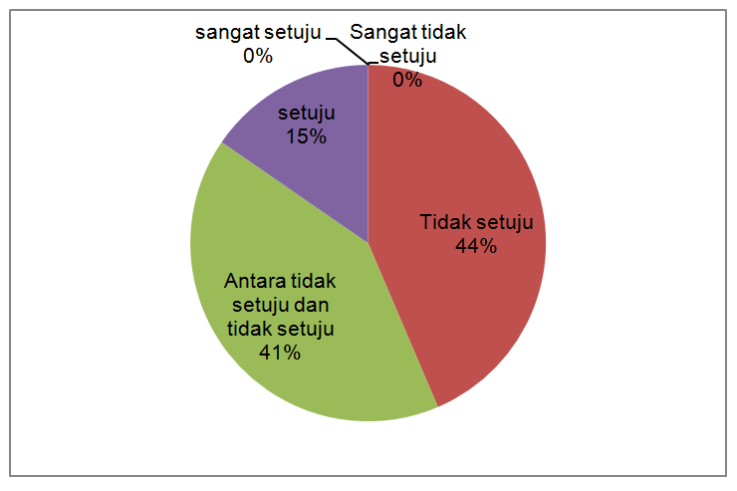

Gambar 1: Hasil penilaian website RI memiliki tampilan yang menarik

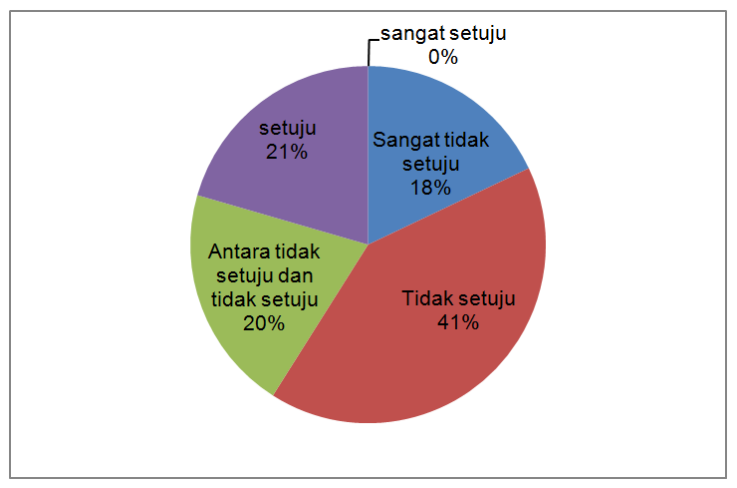

Gambar 2: Hasil penilaian website RI memiliki tampilan yang mudah dipahami

Dari analisa hasil eyetracking untuk task III, ditemukan adanya kesulitan pada saat hendak menggunakan fitur sortir produk karena dalam website RI menggunakan istilah standar tanpa adanya keterangan lebih lanjut yang menujukan bahwa hal tersebut adalah fitur untuk sortir. Dari beberapa hasil gaze replay atau gaze plot, beberapa responden mencoba mencari fitur sortir di dekat area filter produk (Gambar 7). Kesulitan lain yang dialami oleh responden adalah menemukan informasi mengenai produk yang dipilih.

Dari analisa eyetracking untuk task IV, diketahui bahwa beberapa responden membutuhkan waktu yang lebih lama untuk menemukan fitur wishlist. Beberapa responden memperhatikan ikon collection, cart, dan points sebelum akhirnya mencoba akses wishlist dengan memilih ikon collection (Gambar 8). Kendala lain yang ditemukan pada saat pelaksanaan task IV adalah tidak menggunakan button perbarui untuk memperbarui jumlah unit yang dipesan sehingga jumlah unit tidak diperbarui. Beberapa responden mengira pada saat pengisian jumlah unit yang dibeli sudah memperbarui jumlah se- 


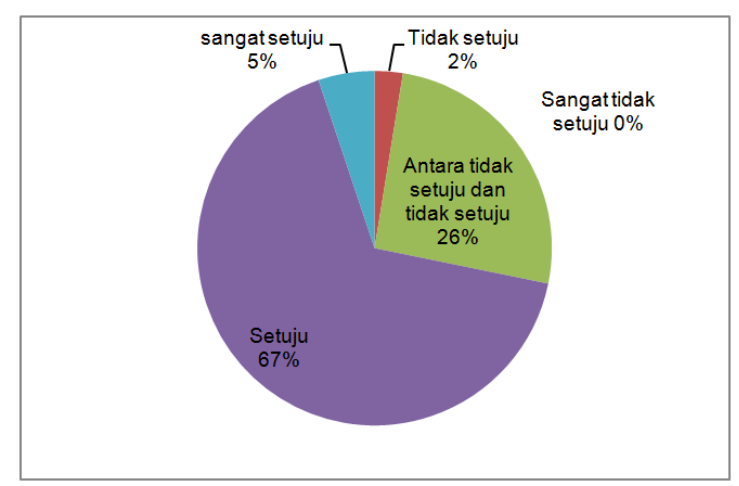

Gambar 3: Hasil penilaian sistem pemesanan pada website RI mudah digunakan

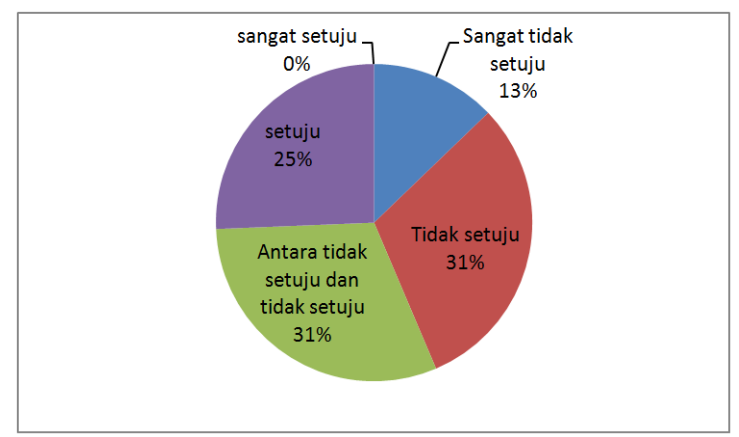

Gambar 4: Hasil penilaian website RI memiliki informasi (deskripsi produk, pemesanan, pembayaran, dan sebagainya) yang jelas

cara otomatis. Namun, ketika melihat nominal yang dibayarkan belum berubah, responden baru menyadari jika perlu memilih button perbarui (Gambar 9).

Dari hasil pengujian kemampupakaian website RI pada saat pelaksanaan task II sampai dengan task IV dengan menganalisa gaze replay, maka permasalahan yang dihadapi pengguna website dapat dilihat pada Tabel 3.

Heatmap digunakan untuk mengetahui jumlah fiksasi yang dilakukan oleh semua responden pada halaman tertentu. Dari hasil penelitian yang dilakukan, diperoleh heatmap yang dapat dilihat pada Gambar 10. Warna pada heatmap menunjukkan banyaknya fiksasi yang terjadi. Semakin merah warna pada area tertentu menujukan semakin banyak fiksasi yang terjadi pada area tersebut.

Berdasarkan heatmap yang diperoleh, terdapat 3 area yang paling banyak terjadi fiksasi. Area 1 bagian daftar kategori, Area 2 bagian iklan yang berada di tengah homepage, dan Area 3 bagian kanan atas homepage. Pada saat diberikan task I, responden diberikan waktu untuk mejelajahi website RI, sehingga responden melihat jenis

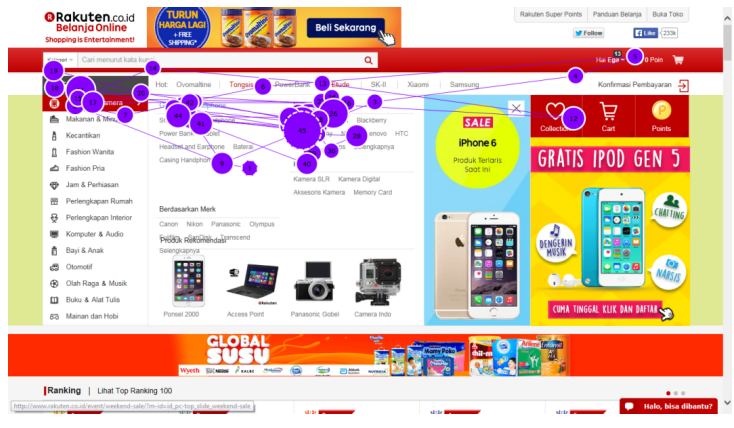

Gambar 5: Gaze plot responden saat membuka kategori

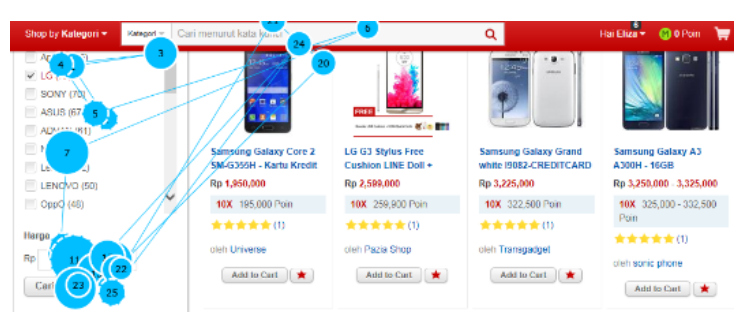

Gambar 6: Gaze plot responden saat memasukan rentang harga

produk yang diminati dengan melihat bagian kategori (Area 1). Area 2 memiliki fiksasi yang cukup banyak karena area iklan yang cukup besar dan berubah-ubah sehingga banyak responden yang melihat berulangkali ke area 2. Area 3 memiliki fiksasi yang cukup banyak karena responden memperhatikan informasi yang ditampilkan di area 3, seperti: profile pengguna, ikon collection, cart, dan points. Sebagian besar responden juga melihat iklan yang berada di bawah area 3. Selain ketiga area tersebut, area lain yang cukup banyak dilihat oleh responden adalah bagian ranking dan bagian time sale. Responden tertarik pada bagian tersebut karena label diskon sehingga responden ingin melihat produk yang sedang diskon dan besarnya diskon yang diberikan. Analisis area of interest (AOI) dilakukan untuk menganalisis penempatan iklan pada homepage. Matriks yang digunakan adalah time to first fixation dan fixation duration yang diukur pada saat pelaksanaan task I. AOI dalam penelitian ini terbagi kedalam 4 (empat) area yang dapat dilihat pada Gambar 11.

Matriks time to first fixation dapat menilai keefektifan peletakan iklan dengan melihat jumlah responden yang melihat ke setiap area. Dari hasil yang diperoleh, responden paling banyak melihat pertama kali ke area 2. Matriks time to first fixation dapat dilihat pada Tabel 4.

Matriks fixation duration pada Tabel 5 menu- 


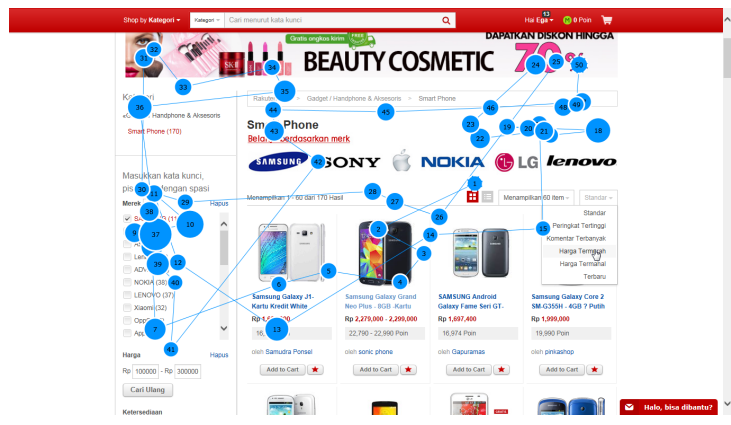

Gambar 7: Gaze plot responden saat mencari fitur sortir produk

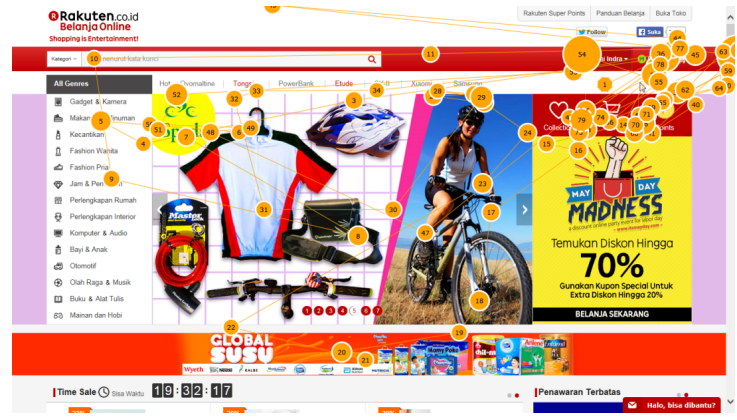

Gambar 8: Gaze plot responden saat mencari fitur wishlist

jukan berapa kali terjadi fiksasi pada area dalam AOI, rata-rata waktu tiap fiksasi pada AOI, dan jumlah waktu fiksasi untuk AOI tersebut. Area 2 merupakan area yang paling lama dilihat karena berukuran cukup besar dan berada di tengah homepage, sedangkan area 4 merupakan area yang paling sedikit dilihat oleh pengguna. Matriks fixation duration dapat digunakan untuk menganalisa isi iklan yang terdapat pada AOI. Karena durasi fiksasi pada area terbilang cukup singkat, maka diperlukan tampilan iklan dengan informasi yang singkat, tidak padat, serta menarik.

\subsection{Usulan Perbaikan Website}

Usulan perbaikan website RI berdasarkan hasil analisa gaze replay, meliputi 2 bagian, yaitu: bagian subkategori dan bagian ikon collection. Selain itu, diusulkan perbaikan untuk penempatan iklan pada homepage website RI berdasarkan analisis area of interest. Perbaikan yang dilakukan pada bagian subkategori adalah penyusunan subkategori berdasarkan abjad dan menata sususannya. Perbaikan pada bagian subkategori dapat dilihat pada Gambar 12(b). Perbaikan yang dilakukan pada bagian ikon collection agar pengguna dapat menggunakan/ mengakses fitur wishlist secara cepat dengan

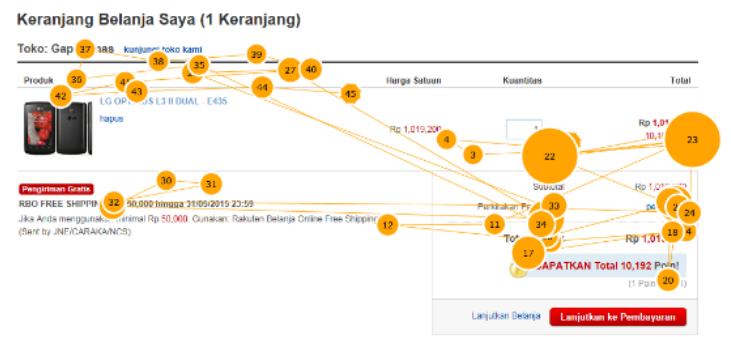

Gambar 9: Gaze plot responden saat memperbarui jumlah unit yang dibeli

Tabel 3: Rekapitulasi hasil analisis gaze replay

\begin{tabular}{|c|l|}
\hline No & Hasil Analisis \\
\hline 1 & Tulisan pada subkategori tidak tertata rapi \\
\hline 2 & $\begin{array}{l}\text { Responden tidak mengerti arti Masukan kata } \\
\text { kunci, pisahkan dengan spasi }\end{array}$ \\
\hline 3 & $\begin{array}{l}\text { Responden kesulitan mengisi harga pada } \\
\text { kolom rentang harga }\end{array}$ \\
\hline 4 & $\begin{array}{l}\text { Responden tidak menyadari icon untuk sort } \\
\text { produk }\end{array}$ \\
\hline 5 & $\begin{array}{l}\text { Responden kesulitan mencari informasi dari } \\
\text { deskripsi produk }\end{array}$ \\
\hline 6 & Responden tidak memahami icon collection \\
\hline 7 & $\begin{array}{l}\text { Responden tidak memahami icon daftar } \\
\text { keinginan saya }\end{array}$ \\
\hline 8 & $\begin{array}{l}\text { Responden tidak mengetahui cara mengubah } \\
\text { kuantitas pesanan }\end{array}$ \\
\hline 9 & $\begin{array}{l}\text { Responden tidak tertarik melihat rangkuman } \\
\text { belanja }\end{array}$ \\
\hline 10 & $\begin{array}{l}\text { Tulisan untuk metode pembayaran kurang } \\
\text { tegas }\end{array}$ \\
\hline
\end{tabular}

mengubah collection menjadi daftar keinginan atau wishlist. Fitur wishlist dapat diakses melalui menu profil pengguna lalu daftar keinginan saya. Namun beberapa pengguna tidak menyadari hal tersebut karena penggunaan istilah yang berbeda untuk fitur wishlist, sehingga dipilih konsistensi istilah untuk fitur wishlist berupa daftar keinginan. Perbaikan dapat ikon fitur wishlist dapat dilihat pada Gambar 13.

Selain itu, pada profil pengguna, terdapat penggunaan istilah yang mirip, yaitu pesanan saya dan pesan saya sehingga dilakukan perubahan penggunaan kata untuk istilah tersebut untuk menekankan perbedaan antara keduanya. Istilah pesan saya diubah menjadi kotak pesan. Perbaikan drop down menuprofil pengguna dapat dilihat pada Gambar 14. Perbaikan dilakukan pada bagian rentang harga dengan memberikan ukuran kotak rentang harga yang lebih besar dan ada pemisah nominal ribuan dalam kotak rentang harga. Selain itu, ditambahkan pula pengatur rentang harga dengan menggunakan garis untuk mempermudah input rentang harga. Perbaikan pada bagian 


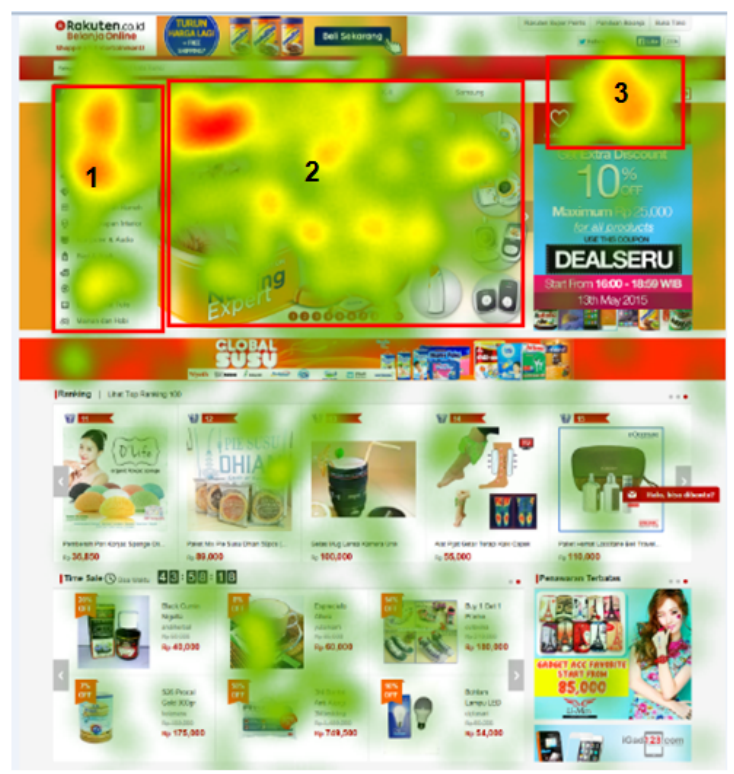

Gambar 10: Heatmap pada task I

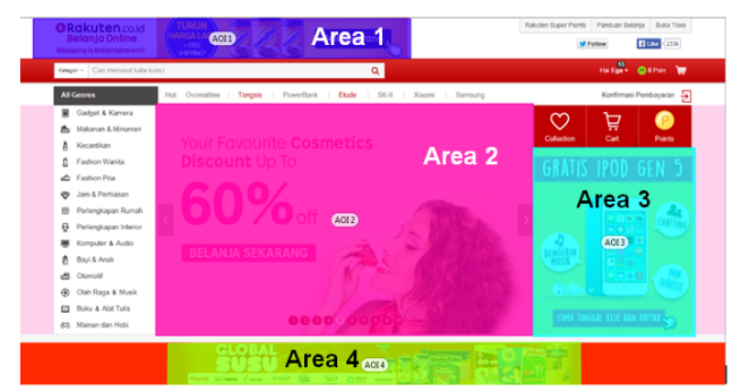

Gambar 11: Area of interest pada homepage

rentang harga dapat dilihat pada Gambar 15.

Perbaikan juga dilakukan untuk fitur sortir produk dengan mengganti istilah standar dengan urutkan berdasarkan. Pengantian istilah ini untuk menunjukkan secara jelas fitur sortir produk. Perbaikan fitur sortir produk dapat dilihat pada Gambar 16.

Perbaikan lain yang dilakukan untuk website Rakuten Indonesia adalah perbaikan ikon untuk fitur menambahkan produk ke dalam keranjang belanja (add to cart), penambahan format tabel di deskripsi produk, perubahan sistem dalam proses mengubah kuantitas pemesanan, dan perubahan tampilan pada pemilihan metode pembayaran. Untuk perbaikan untuk penempatan iklan berdasarkan analisis AOI berupa perbedaan tarif untuk menyewa area iklan. Saat ini tarif iklan untuk area 1 sebesar Rp 5.000.000, area 2 sebesar Rp 15.000.000, area 3 sebesar Rp 3.000.000, dan area 4 sebesar 15.000.000. Dengan begitu, urutan tarif untuk iklan dari yang termahal hingga termurah adalah area 2, area 4 , area 1 , area 3. Berdasarkan time to first fixation, area 2
Tabel 4: Matriks time to first fixation

\begin{tabular}{|c|c|c|}
\hline \multicolumn{3}{|c|}{ Time to First Fixation } \\
\hline Area 1 & Jumlah (responden) & 9 \\
\cline { 2 - 3 } & Rata-rata (detik) & 6,76 \\
\hline Area 2 & Jumlah (responden) & 37 \\
\cline { 2 - 3 } & Rata-rata (detik) & 0,81 \\
\hline Area 3 & Jumlah (responden) & 20 \\
\cline { 2 - 3 } & Rata-rata (detik) & 4,87 \\
\hline Area 4 & Jumlah (responden) & 9 \\
\cline { 2 - 3 } & Rata-rata (detik) & 5,36 \\
\hline
\end{tabular}

Tabel 5: Matriks fixation duration

\begin{tabular}{|c|c|c|}
\hline \multicolumn{3}{|c|}{ Fixation Duration } \\
\hline Area 1 & Jumlah melihat (kali) & 18 \\
\cline { 2 - 3 } & Rata-rata (detik) & 0,28 \\
\cline { 2 - 3 } & Jumlah (detik) & 5,13 \\
\hline Area 2 & Jumlah melihat (kali) & 475 \\
\cline { 2 - 3 } & Rata-rata (detik) & 0,23 \\
\cline { 2 - 3 } & Jumlah (detik) & 114,48 \\
\hline Area 3 & Jumlah melihat (kali) & 39 \\
\cline { 2 - 3 } & Rata-rata (detik) & 0,23 \\
\cline { 2 - 3 } & Jumlah (detik) & 8,9 \\
\hline Area 4 & Jumlah melihat (kali) & 17 \\
\cline { 2 - 3 } & Rata-rata (detik) & 0,19 \\
\cline { 2 - 3 } & Jumlah (detik) & 3,27 \\
\hline
\end{tabular}

merupakan area yang paling banyak dilihat dan paling dahulu dilihat jika dibandingkan dengan area lainnya. Selain itu, area 2 juga memiliki jumlah fiksasi yang paling banyak (475 kali) dan durasi fiksasi yang paling lama $(114,48$ detik). Sedangkan area 4 merupakan area 4 merupakan area dengan jumlah fiksasi dan durasi fiksasi paling kecil. Area 4 dapat dikatakan sebagai area yang jarang dilihat/ diperhatikan oleh pengguna. Area 3 memiliki time to first fixation yang lebih cepat dibandingkan dengan area 1 . Area 3 juga memiliki jumlah fiksasi dan durasi fiksasi yang lebih banyak jika dibandingkan dengan area 1 dan area 4 . Dari hal tersebut, dapat diusulkan untuk pemberian tarif pemasangan iklan dari yang termahal sampai termurah adalah area 2, area 3, area 1, dan area 4 . Selain itu usulan juga diberikan untuk isi dari iklan sebaiknya singkat dan menarik menimbang waktu untuk melihat iklan yang cenderung singkat. Untuk area 2 yang memiliki durasi fiksasi yang lebih banyak dibandingkan area lainnya, dapat dicantumkan informasi yang lebih lengkap dibandingkan dengan area lainnya. Sedangkan untuk area 2, 3, dan 4 yang memang secara area berukuran kecil serta memiliki jumlah dan durasi fiksasi yang kecil, sebaiknya isi iklan lebih menujukkan gambar produk disertai dengan kata yang menarik, seperti diskon, sale, pro- 


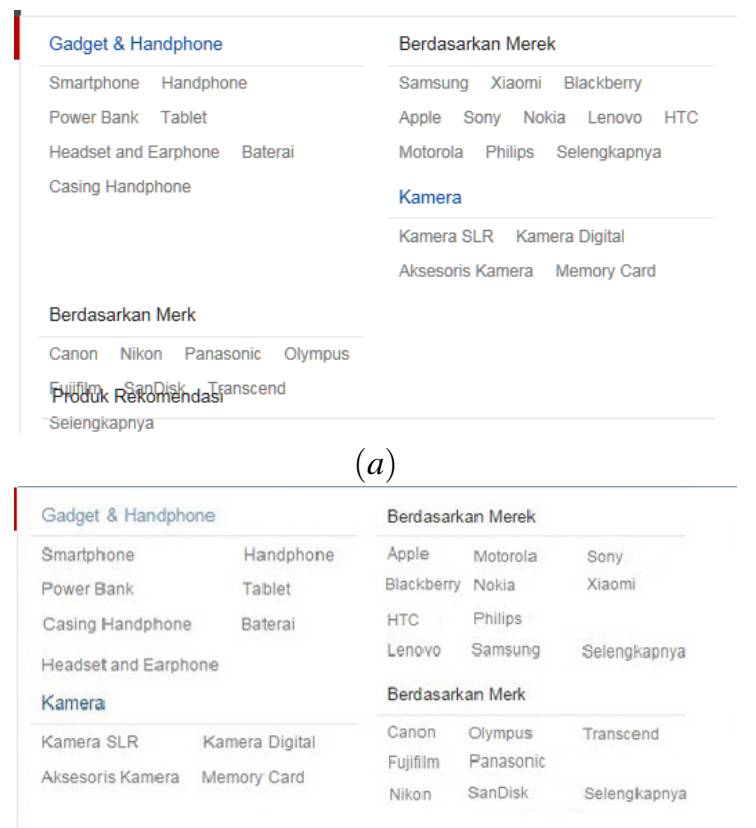

(b)

Gambar 12: Bentuk penyusunan subkategori (a). bentuk awal (b). bentuk usulan

mosi, dan sebagainya. Hasil perbaikan website tersebut belum dapat dievaluasi keberhasilannya dalam mengatasi permasalahan terkait website Rakuten Indonesia karena belum diimplementasikan.

\section{Kesimpulan}

Kesimpulan yang diperoleh dari hasil penelitian ini adalah website Rakuten Indonesia dapat berjalan untuk memenuhi fungsi utamanya sebagai media transaksi jual beli, namun masih belum memenuhi kriteria kemampupakaian. Berdasarkan pengujian kemampupakaian dengan eyetracking, masih ditemui beberapa kesulitan pada saat menggunakan website Rakuten Indonesia. Usulan perbaikan website Rakuten Indonesia dilakukan pada perbaikan tampilan subkategori, perbaikan ikon fitur wishlist, penggunaan istilah yang konsisten, perubahan pada fitur range harga, perubahan pada fitur sortir produk, perbaikan pada format deskripsi produk, perubahan kuantitas pemesanan, serta metode pembayaran. Selain itu diusulkan juga untuk tarif pemasangan iklan pada homepage website Rakuten Indonesia.

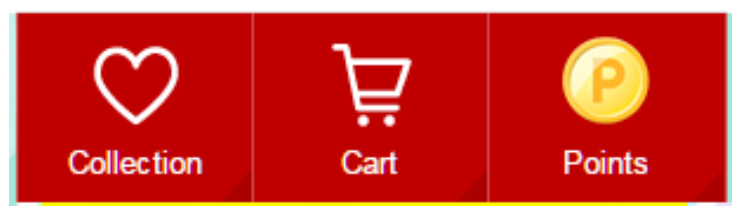

(a)

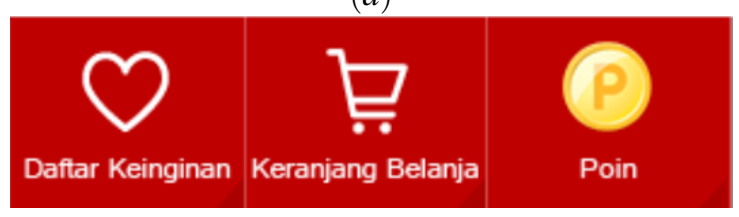

(b)

Gambar 13: Ikon fitur wishlist

(a). ikon awal (b). ikon usulan

\begin{tabular}{|l|l|}
\hline My Rakuten & \multicolumn{1}{|l|}{ Pesanan Saya } \\
\cline { 2 - 2 } Kupon Saya & Kupon Saya \\
Daftar Keinginan Saya & Daftar Keinginan Saya \\
Produk yang Baru Dilihat & Produk yang Baru Dilihat \\
Pesan Saya & Kotak Pesan \\
Akun Saya & Akun Saya \\
\hline Keluar & Keluar \\
\hline
\end{tabular}

(a)

(b)

Gambar 14: Gambar dropdown menu profil pengguna (a). tampilan awal (b). tampilan usulan

\section{Daftar Pustaka}

Chaffey, Dave. (2009). E-business and E-commerce Management: Strategy, Implementation and Practice (4th ed.). Gosport: Ashford Colour Press Ltd.

Holmqvist, K. (2014). Areas of Interest in Eye Movement Data, Diunduh dari: http:/ / www.researchgate.net/publication/ 267548355_Areas_of_Interest_in_Eye_Movement _Data [2015, 3 Maret].

McGrath, E. (2013). Top 9 E-Commerce Usability Guidelines, [Online], Diakses dari: http://usabilitygeek.com/top-9-ecommerce-usability-guidelines/ [2015, 3 Maret].

Nielsen, J. (2012, 4 Januari), Usability 101: Introduction to Usability, [Online], Diakses dari: http://www.nngroup.com/articles/ usability-101-introduction-to-usability / [2015, 3 Maret]. 
Nielsen, J., dan Pernice, K., (2009). How to Conduct Eyetracking Studies. Diunduh dari http://www.nngroup.com/reports/how-toconduct-eyetracking-studies.

Ross, J. (2009). Eyetracking: Is It Worth It? Diunduh dari http:/ / www.uxmatters.com/mt/ archives/2009/10/eyetracking-is-it-worth-it. php

Rouse, M. (2013). Eye tracking (Gaze Tracking). Diunduh dari: http://whatis. techtarget.com/definition/eye-trackinggaze-tracking

Rubin, J., dan Chisnell, D. (2008). Handbook of Usability Testing (2nd ed.). Indiana: Wiley Publishing Inc.

Statista. (2015). Number of internet users in Indonesia from 2013 to 2018 (in millions) Diunduh dari: http://www.statista.com /statistics/254456/number-of-internet-usersin-indonesia /

Tobii Technology (2012). User Manual Tobii Studio. Diunduh dari: http://www.tobii.com/en/eye-trackingresearch/global/library/manuals/

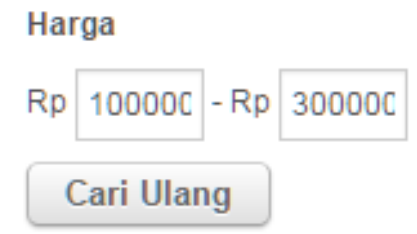

(a)
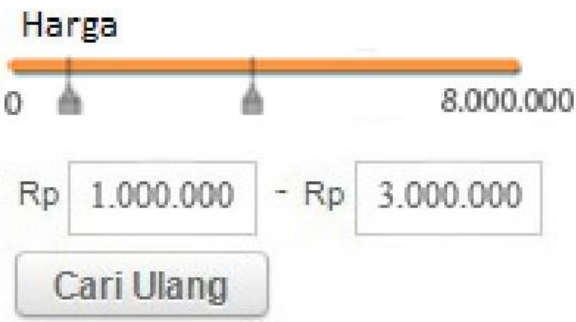

(b)

Gambar 15: Gambar bagian rentang harga (a). tampilan awal (b). tampilan usulan

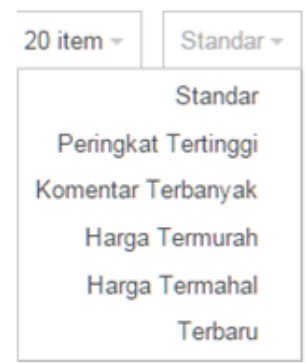

(a)

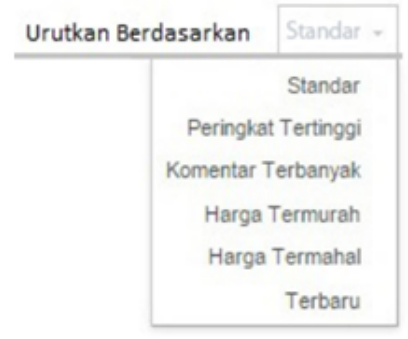

(b)
Gambar 16: Gambar fitur sortir produk (a). tampilan awal (b). tampilan usulan 